\title{
Environmental Entomology
}

\author{
ENTOMOLOGICAL SOCIETY OF AMERICA
}

VOL. 6

DECEMBER 15, 1977

NO. 6

\section{Attractancy of Racemic Disparlure and Certain Analogues to Male Gypsy Moths ${ }^{1}$ and the Effect of Trap Placement}

\author{
R. T. CARDÉ,,$^{2,3}$ C. C. DOANE, ${ }^{4}$ J. GRANETT, ${ }^{4,5}$ A. S. HILL, \\ J. KOCHANSKY, ${ }^{2,8}$ AND W. L. ROELOFS
}

\begin{abstract}
Traps hung on small trees of 3-8 $\mathrm{cm}$ diam and baited with racemic epoxides, hydrocarbons and other analogues related to racemic cis-7,8-epoxy-2-methyloctadecane (disparlure) resulted in male Lymantria dispar L. (gypsy moth) catches statistically indistinguishable from those of unbaited traps. Only ( \pm )-disparlure yielded trap catches statistically above the level of unbaited traps. However, trap placement on trees of ca. $0.5 \mathrm{~m}$ diam produced appreciable trap catches, even in unbaited traps.
\end{abstract}

The female-emitted pheromone of the gypsy moth, Lymantria dispar L., was characterized as cis-7,8epoxy-2-methyloctadecane and named "disparlure" (Bierl et al. 1970). Sarmiento et al. (1972), Adler et al. (1972) and Schneider et al. (1974) reported that $( \pm)$-epoxide analogues of disparlure were only slightly attractive when contrasted with $( \pm)$-disparlure. Sheads et al. (1975) evaluated the attractancy of diverse compounds structurally similar to disparlure but lacking the epoxide moiety. Sheads et al. suggested that receptor response is not completely specific to the epoxy group, because these analogues possessed attractancy levels below that of ( \pm )-disparlure but apparently above those of the $( \pm)$ epoxide analogues. We report here an investigation of the male trap-catch evoked by certain of these and other compounds related to disparlure.

\section{Materials and Methods}

\section{Chemicals}

The $( \pm)$-disparlure and 2-methyl-(Z)-7-octadecene were obtained from Farchan Chemicals and contained $15 \%(E)$ isomers. The 2-methyl alkanes (Table 2, Treatments 7-8) were obtained from $\mathrm{K}$ and $\mathrm{K}$ Laboratories. The ( \pm )-cis-8,9-epoxy-2-methyloctadecane (Treatment 9 ) was supplied by Zoecon Corporation. The epoxides of treatments 10-12 were prepared by epoxidation of the corresponding olefins

\footnotetext{
${ }^{1}$ Lepidoptera: Lymantridae. Received for publication May $18,1977$.

2 Department of Entomology, New York State Agricultura Experiment Station, Geneva 14456 .

$\checkmark$ Present address: Department of Entomology, Michigan State University, East Lansing $\mathbf{4 8 8 2 4}$.

- Department of Entomology The Connecticut Agricultura Experiment Station, New Haven 06504.

Present address: Department of Entomology, University of Maine, Orono 04473.

Present address: USDA, ARS, Beltsville, MD 20705.
}

with $m$-chloroperbenzoic acid in benzene and were of $>95 \%$ purity. The 2-methyl- $(Z)-6$-octadecene was obtained by reaction of triphenyl(6-methylheptyl) phosphonium bromide in DMF with sodium methoxide and dodecanal. The other $(Z)$ alkenes were prepared in a similar manner from the appropriate starting materials. Compounds of treatments $13-17$ were prepared by the procedures of Sheads et al. (1975) and were of comparable purity. The trioctanoin was obtained from Eastman Organic Chemicals. All compounds were racemic where optical activity is formally possible.

\section{Field Tests}

Trapping was conducted in oak forests (Quercus spp.) in Wolf's Den State Park in Pomfret, Conn. in July, 1975. All test chemicals were dispensed in $100 \mu \mathrm{l}$ petroleum ether either onto cotton wicks of $1 \mathrm{~cm}$ diam $\times 1 \mathrm{~cm}$ length or onto $5 \times 9-\mathrm{mm}$ rubber septa (A. H. Thomas Co.). Charged dispensers were placed inside modified Granett (1973) type traps. The traps were constructed of opaque, white polystyrene $0.5 \mathrm{~mm}$ thick. The trap consisted of a cylinder $18 \mathrm{~cm}$ in diam and $25 \mathrm{~cm}$ in length. Funnel cones at each end extended $8 \mathrm{~cm}$ into the cylinder. The entrance port at the end of each funnel was $2.5 \mathrm{~cm}$ in diam. Insects were killed by a $2 \times 2-\mathrm{cm}$ plastic strip containing $18 \%$ 2,2-dichlorovinyl dimethyl phosphate. In all tests, traps were hung at a height of $1.8 \mathrm{~m}$ and separated by $10 \mathrm{~m}$. In test 1 , traps were hung on the side of trees of $25-50 \mathrm{~cm}$ diam. In test 2, the traps were rebaited and hung from sapling trees of $3-8 \mathrm{~cm}$ diam that had been cleared of branches and leaves within $50 \mathrm{~cm}$ of the trap and that were situated at least $2 \mathrm{~m}$ from trees of greater diam. The appreciable catches in the un- 
Table 1.-Field captures of male Lymantria dispar with racemic disparlure $[( \pm)$-cis-7,8-epoxy-2. methyloctadecane] and its olefin (2-methyl-(Z)-7. octadecene). Traps were hung on trees of 25-50 cm diam. Test conducted in Pomfret, Conn. from July 10-18, 1975.

\begin{tabular}{llc}
\hline Treatment & Dispenser & Males $/$ trap \\
\hline $1000 \mu \mathrm{g}$ disparlure & rubber septum & $16.1 \mathrm{ab}$ \\
$100 \mu \mathrm{g}$ disparlure & rubber septum & $16.7 \mathrm{ab}$ \\
$10 \mu \mathrm{g}$ disparlure & rubber septum & $9.8 \mathrm{bc}$ \\
$100 \mu \mathrm{g}$ disparlure & cotton wick & $22.0 \mathrm{a}$ \\
$+5 \mathrm{mg}$ trioctanoin & & $16.8 \mathrm{ab}$ \\
$15 \mu \mathrm{g}$ disparlure & cotton wick & $2.1 \mathrm{c}$ \\
olefin $1000 \mu \mathrm{g}$ & cotton wick & $6.6 \mathrm{c}$ \\
$100 \mu \mathrm{g}$ & cotton wick & $5.1 \mathrm{c}$ \\
$10 \mu \mathrm{g}$ & cotton wick & $24.2 \mathrm{a}$ \\
\hline
\end{tabular}

- Means followed by the same letter are not significantly different at the $5 \%$ level according to Student-Newman-Keuls multiple range test.

baited traps in Test 1 are not related to accidental contamination. Extreme care was taken to avoid unintentional contact of traps with any except the stated lure. The traps from Test 1 were used in Test 2, indicating in the case of unbaited traps that the high catches in the unbaited traps in Test 1 cannot be ascribed to disparlure contamination. Treatments were set out in a randomized complete block design with 5 replicates. Data were transformed to $\sqrt{\mathrm{X}}$ and submitted to analyses of variance.

\section{Results and Discussion}

Richardson et al. (1976) and Cardé et al. (1975) observed pheromone-activated vertical (up and down) in-flight "investigation" by males of vertical silhouettes such as trees. In test 1 (Table 1), the trap catches effected by several formulations of $( \pm)$ disparlure were evaluated with modified Granetttraps placed on trees of ca. $0.5 \mathrm{~m}$ diam. The substantial catches in unbaited traps suggested that some males were captured following pheromone-activated "searching" (walking while wing fanning) on tree trunks and traps rather than by positive anemotaxis to an odor source. The olefin, previously reported to lower trap catch when emitted with ( \pm )-disparlure (Cardé et al. 1973), also diminished the catch relative to the unbaited controls when emitted alone. Data from test 1 suggested that evaluations of lure attractancy should be conducted with traps isolated from visual cues such as tree trunks which may elicit "investigative" behav" or and thereby affect trap catch.

In the 2nd test (Table 2), traps were isolated from vertical silhouettes larger than $8 \mathrm{~cm}$ in diam. Racemic disparlure was the most effective lure evaluated. All other treatments were statistically indistinguishable at the $5 \%$ level from unbaited traps. These data are in contrast to the high trap counts [relative to $( \pm)$-disparlure] for the compounds in treatments 13-17 reported by Sheads et al.
(1975). The epoxides of treatments 10-12 had been evaluated by other tests (Schneider et al. 1972, Sarmiento et al. 1972, Adler et al. 1972) with results similar to ours.

In the tests of Sheads et al. (1975), overloading of small traps ( $10 \mathrm{~cm}$ long $\times 5 \mathrm{~cm}$ diam) may have depressed the catches of ( \pm )-disparlure. As Sheads et al. utilized no unbaited traps and did not analyze their data statistically, their postive trap catches are difficult to interpret. The Granett-type trap used in our tests has a capacity of over a thousand males and its efficiency of capture is unaffected by trap load (Granett 1973, Cardé et al. 1977). Test 2 indicated that of the compounds investigated only ( \pm )-disparlure elicited a positive trap catch increase over unbaited traps. However, $( \pm)$-disparlure is a relatively weak attractant and is not likely to be the natural pheromone. Recently available $(+)$-disparlure (Iwaki et al. 1974, Mori et al. 1976) effects ca. a 5-10 fold greater male catch than ( \pm )-disparlure (Cardé et al. 1977, Miller et al. 1977).

Table 2.-Field captures of male Lymantria dispar with racemic disparlure and related compounds on cotton wicks. Traps were hung on trees of 3-8 $\mathrm{cm}$ diam and were $>2 \mathrm{~m}$ away from trees $>8 \mathrm{~cm}$ in diam. Tested in Pomfret, Conn. from July 20-31, 1975.

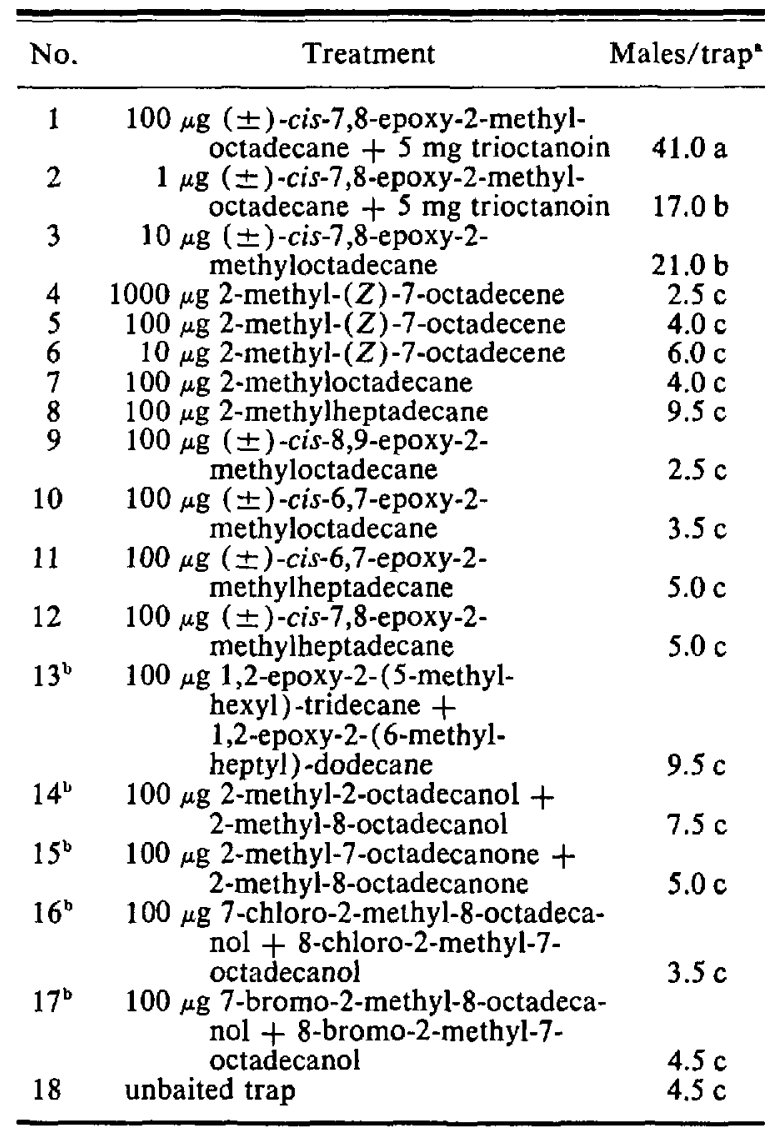

Means followed by the same letter are not significantly different at the 5\% level according to Student-Newman-Keuls multiple range test.

$b$ Mixture of the 2 isomers. 


\section{Acknowledgment}

We thank D. Hostage for his assistance in the field studies, G. Milicevic for synthesis of the epoxides in treatments 10-12 and Dr. C. Henrick for the gift of treatment 9 .

\section{REFERENCES CITED}

Adler, V. E., M. Beroza, B. A. Bierl, and R. Sarmiento. 1972. Electroantennograms and field attraction of the gypsy moth sex attractant disparlure and related compounds. J. Econ. Entomol, 65: 679-81.

Bierl, B. A., M. Beroza, and C. W. Collier. 1970. Potent sex attractant of the gypsy moth: isolation, identification and synthesis. Science 170: 87-89.

Cardé, R. T., C. C. Doane, T. C. Baker, S. Iwaki, and S. Marumo. 1977. Attractancy of optically active pheromone for male gypsy moths. Environ. Entomol. 6: 768-72.

Cardé, R. T., C. C. Doane, J. Grannett, and W. L. Roelofs. 1975. Disruption of pheromone communication in the gypsy moth: Some behavioral effects of disparlure and an attractant modifier. Environ. Entomol. 4: 793-6.

Cardé, R. T., W. L. Roelofs, and C. C. Doane. 1973. Natural inhibitor of the gypsy moth sex attractant. Nature. 241: 474-5.

Granett, J. 1973. A disparlure-baited box trap for capturing large numbers of gypsy moths. J. Econ. Entomol. 66: 359-62.

Iwaki, S., S. Marumo, T. Saito, M. Yamada, and K. Katagiri. 1974. Synthesis and activity of optically active disparlure. J. Am. Chem. Soc. 96: 7842-4.

Miller, J. R., K. Mori, and W. L. Roelofs. 1977. Field trapping and electroantennogram studies on the gypsy moth using disparlure enantiomers. J. Insect Physiol. (In press).

Mori, K., T. Takigawa, and M. Matsui. 1976. Stereoselective synthesis of optically active disparlure, the pheromone of the gypsy moth (Porthetria dispar L.). Tetrahedron Letters 44: 3953-6.

Richerson, J. V., E. A. Cameron, and E. A. Brown. 1976. Sexual activity of the gypsy moth. Am. Midl. Nat. 95: 299-312.

Sarmiento, R., M. Beroza, B. A. Bierl, and J. G. R. Tardif. 1972. Activity of compounds related to disparlure, the sex attractant of the gypsy moth. J. Econ. Entomol. 65: 665-7.

Sheads, R. E., M. Beroza, and E. C. Paszek. 1975. Chemicals related to the gypsy moth sex pheromone as attractants and as synergists or inhibitors of the pheromone. J. Agr. Food. Chem. 23: 60-64.

Schneider, D., R. Lange, F. Schwarz, M. Beroza, and B. A. Bierl. 1974. Attraction of male gypsy and nun moths to disparlure and some of its chemical analogues. Oecologica 14: 19-36. 